\title{
Alternating Hemiplegia of Childhood in a Child Misdiagnosed as Intractable Epilepsy
}

Sir, Neurofibromatosis type 1 (NF1) is an autosomal-dominant disorder characterized by café au lait spots, skin-fold freckles, lisch nodules, cutaneous, subcutaneous, and plexiform neurofibromas, optic gliomas, and bony lesions. ${ }^{[1]}$ Alternating hemiplegia of childhood (AHC) is a predominantly sporadic neurodevelopmental disorder characterized by transient repeated attacks of hemiplegia on either side of the body. Other paroxysmal symptoms such as tonic and dystonic attacks, autonomic disturbances, seizures, and oculomotor abnormalities could occur. ${ }^{[2]}$ Here, we present an NF1 patient with AHC who misdiagnosed as intractable epilepsy.

A 5-year-old girl presented to our hospital with a history of intractable epilepsy for 3 years. She was born the first child of a nonconsanguineous marriage at term following an uneventful pregnancy. She had first episode of the left hemiplegia at 2 years, which spontaneously recovered after $6-8 \mathrm{~h}$. On examination, many cafe au lait spots had found on her skin. Magnetic resonance imaging (MRI) of the brain was shown hyperintense lesions in cerebellum, brain stem, and subcortical regions on T2-weighted images. That state was typical for unidentified bright objects of NF1. An electroencephalogram (EEG) was had performed and found normal. Because of her clinical and laboratory findings, NF1 and epilepsy were diagnosed. She has no family history of NF1 disease. Although she had treated with phenobarbital, the patient had multiple acute attacks of hemiparesis with eye deviation. The attacks were intermittent and of varying location and resolved gradually. On several other admissions, documented findings were mainly of weakness on one side, most commonly the right. This was sometimes accompanied by excessive sweating. They had thought that seizures with Todd's paralysis. She had taken several medications including phenobarbital, carbamazepine, valproic acid, and levetiracetam.
Although she had use two antiepileptic drugs (AEDs) for seizures, her attacks continued. In our examination, her vital signs, including the blood pressure, were normal. Her height and weight were normal for her age. Many cafe au lait spots and axillary freckles were found on her body. There were no subcutaneous neurofibromas. Ophthalmic examination was revealed optic glioma on the right eye. The remaining of the physical and neurological examination was unremarkable. The developmental assessment was normal. The repeat EEG was made and found normal. Her cerebral MRI was compatible with NF1 [Figure 1]. Clinical and laboratory findings suggested AHC, mutation analysis of the ATP1A3 gene performed, and revealed a novel mutation p.P842P (c. $2526 \mathrm{G}>\mathrm{A}$ ). After the diagnosis, the patient treated with flunarizine, and she has been asymptomatic for 5 months.

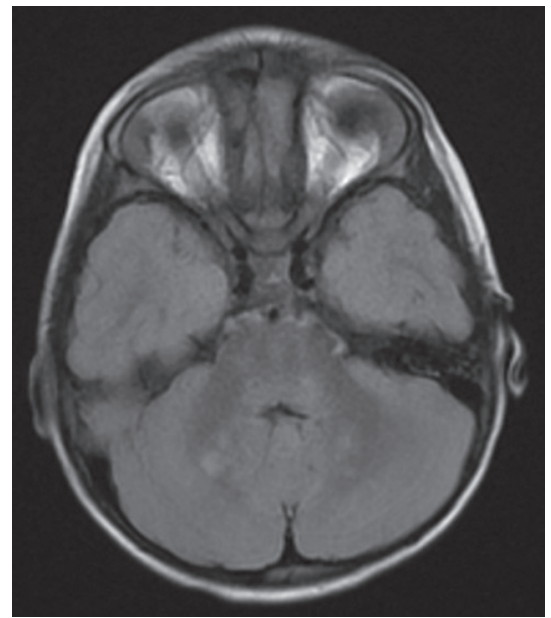

Figure 1: Cerebral magnetic resonance imaging showed hyperintesive lesions in cerebellum, brain stem, and subcortical regions 
NF1 is a common, genetically transmitted neurodevelopmental disorder with a high potential cause of subcortical focal brain lesions. Neurologic problems in NF1 vary and include malignant brain tumors, cognitive and attention deficits, headaches, and seizures. ${ }^{[1]}$ Previous reports have estimated that seizures occur in approximately $4 \%-7 \%$ of individuals with NF1. ${ }^{[3]} \mathrm{AHC}$ is a rare clinical picture that can manifest before the age of 4 years and presents dystonic movements and nystagmus as well as progressive intellectual and motor impairment. These episodes can last from a few minutes to some days. Most cases are sporadic. Its incidence is reported to be around one in 1 million children. ${ }^{[4]}$ In addition, half of the children with AHC may have epilepsy, and these seizures are usually quite distinct from AHC attacks in their manifestations although they may occur simultaneously. ${ }^{[4]}$ If an EEG is recorded during the seizure, it usually shows an appropriate abnormality, but between seizures the EEG is normal. We detected normal ictal EEG during her attack. In addition, her former repeat EEG was also normal.

Treatment with flunarizine was used and presented good results, according to other reports, and reduced the number and intensity of the hemiplegia crises. ${ }^{[4]}$ Recently, topiramate has been found effective in a few children with AHC. ${ }^{[5]}$ After the diagnosis, we stopped AEDs and flunarizine was started. After flunarizine therapy, the attacks were not seen.

The diagnosis of AHC depends on the characteristic clinical features, and several authors correlated it with migraine. ${ }^{[2]}$ The spectrum of clinical symptoms of AHC is broad that makes difficulty differential diagnosis. AHC is commonly misdiagnosed as epilepsy.

In conclusion, NF1 and AHC, which are two separate morbidities may also coexist in the same patient and our patient is the first example in the literature. In addition, epilepsy may be seen in the NF1 and also AHC patients. If AEDs have no effect on the seizures in the patients with NF1, AHC should be considered differential diagnosis.

\section{Financial support and sponsorship}

Nil.

\section{Conflicts of interest}

There are no conflicts of interest.
Faruk Incecı, Ozlem M. Herguner

Department of Pediatric Neurology, Medical Faculty, Cukurova University, Adana, Turkey

Address for correspondence: Dr. Faruk Incecık, Toros Mah, Barış Manço Bul. 78178 Sok. Yeşilpark Evleri, Kat: 7, No: 13, Çukurova, Adana, Turkey. E-mail: fincecik@yahoo.com

\section{REFERENCES}

1. Friedman JM, Birch PH. Type 1 neurofibromatosis: A descriptive analysis of the disorder in 1,728 patients. Am J Med Genet 1997;70:138-43.

2. Mikati MA, Kramer U, Zupanc ML, Shanahan RJ. Alternating hemiplegia of childhood: Clinical manifestations and long-term outcome. Pediatr Neurol 2000;23:134-41.

3. Vivarelli R, Grosso S, Calabrese F, Farnetani M, Di Bartolo R, Morgese $\mathrm{G}$, et al. Epilepsy in neurofibromatosis 1. J Child Neurol 2003;18:338-42.

4. Neville BG, Ninan M. The treatment and management of alternating hemiplegia of childhood. Dev Med Child Neurol 2007;49:777-80.

5. Di Rosa G, Spanò M, Pustorino G, Ferrari MD, Stam AH, Sgrò DL, et al. Alternating hemiplegia of childhood successfully treated with topiramate: 18 months of follow-up. Neurology 2006;66:146.

This is an open access article distributed under the terms of the Creative Commons Attribution-NonCommercial-ShareAlike 3.0 License, which allows others to remix, tweak, and build upon the work non-commercially, as long as the author is credited and the new creations are licensed under the identical terms.

\begin{tabular}{|l|l|}
\hline \multicolumn{2}{|c|}{ Access this article online } \\
\hline Quick Response Code: & Website: \\
\hline
\end{tabular}

How to cite this article: Incecik F, Herguner OM. Alternating hemiplegia of childhood in a child misdiagnosed as intractable epilepsy. J Neurosci Rural Pract 2016;7:S130-1. 